\title{
Promotion of Renewable Energy Technologies in Sub-Sahara Africa Via Biomass Energy Technology
}

\author{
Nya Joe Jacob \\ Physics Department, University of the Gambia, Banjul, Gambia, West Africa
}

\begin{abstract}
There are various biomass energy technologies with imbalanced application status spread all over Sub-Sahara Africa. Currently, some biomass technologies have been developed maturely in the market such as biogas, that can be economically competitive, commercially developed, and applied in large scale, while other technologies are in the early stage of commercial applications, that need subsidies and other financial incentives to encourage them in the market. These include biomass power, biomass pallet fuel, biofuels from non-grain feedstock, etc. There are also many emerging biomass technologies which are at R\&D and demonstration stage and are expected to develop into industrial and commercial applications, such as biological ethanol fuel from cellulose and biodiesel from oil plants. Due to the differences in terms of technology maturity, development stage, market competitiveness, and future perspectives of the various biomass technologies, the obstacles can be different, the needed incentives also vary. It is an important task for Sub-Sahara African Countries to study and design a biomass energy development program to ensure implementation of the region's biomass energy development objectives. The biomass energy development program in Sub-Sahara Africa should include assessment of various biomass technology status and objectives, development of approaches in biomass technology research and development, pilot projects, demonstration, and application promotions, and identify supporting incentives in techniques and regulations.
\end{abstract}

Keywords: Biomass Energy Technology; Sub-Sahara Africa; Global climate change; Quantitative Assessment; Promotion of renewable energy

\section{INTRODUCTION}

The increase in energy demand makes Sub-Sahara African Country face tougher challenges in the energy supply. To ensure a stable, cost-effective, clean, and secure energy supply will be an important task for a sustainable development in Sub-Sahara Africa. Conventional energy resources are scarce in some Sub-Sahara African State especially lack of oil and natural gas resources. This has become a critical factor affecting the social and economic growth. While strengthening both conventional energy exploitation and energy saving campaigns, it will be urgent to reform the current energy consumption structure into a multiple energy sources and clean energy approach.

Depending significantly on petroleum, Sub-Sahara Africa becomes the largest consumer country in the continent. This implies that Sub-Sahara African countries faces more challenges in pollution control and green house gas emission than other countries in the continent. According to the statistics, $60 \%$ of the $\mathrm{SO}_{2}$ emission is due to fossil fuel combustion, which has become major air pollutant such that one third of the land is polluted 
by acid rains. The serious environmental pollution and air quality problems have severely affected our social and economic development and threatened people's health. A better energy production system with reduced pollutant discharge has become a must if we want to be a sustainable economy.

The global climate change has been a threat for all peoples. It has been a common interest for the international community to take measures to curb the green house gas emission and face the challenges of climate change and slow down its impact on earth. Many nations have committed to reduce their GHG emissions at different levels.

Sub-Sahara Africa must look at the domestic requirement of pollution control, environment protection, and sustainable development. Without taking an active role, the climate change issues will even become one of the large uncertain factors for our future economic development. The government must attached great importance in coping with the global climate. According to the international best practice, improving energy efficiency and developing renewable energy will be two of the most effective measures. Sub-Sahara Africa has committed development of renewable energy technologies as important means to deal with global warming and emission reduction. According to its long-term renewable energy development plan, they expects to reduce $15-20 \%$ of green house gas emission by using RE sources by 2020. Sub-Sahara African Country is a biomass resource rich country with variety of biomass applications for electricity, biogas, liquid bio-fuel, and solid fuels. The applications of biomass energy were only after solar thermal and far more than wind power production. Biomass energy has become an important part of renewable energy applications.

Among many renewable and alternative energy technologies, biomass energy is currently the only energy product that can substitute liquid petroleum fuel. Biomass is the only renewable energy that human efforts can be involved in the entire process of collection, storage, transport, and energy transformation. Biomass power stations (CHP) can provide electricity for power network peak adjustment while wind power and solar PV must be provided with peak adjustment systems.

Biomass energy applications can provide employment opportunities for local farmers and increase farmers' income. Development of biomass energy will facilitate longer agriculture production chain and develop new industries in rural areas. The industry will help more income for local farmers and support more advanced agriculture sector in the same time. According to estimation, a $25 \mathrm{MW}$ biomass fuel generation turbine system can produce electricity of 130 million kilowatts each year if running 6000 hours. It can be millions dollars value added. Over 1000 jobs can be provided for local farmers in straw collection, transportation, and processing. This will be very important for local economy in terms of solving rural labors, increasing local government income, driving local industry and service sector, improving rural economy, and upgrade the Sub-Sahara Africa's agriculture sector competitiveness in the end.

Biomass development can effectively avoid in-field fire of crop straws, livestock waste discharge, and environment pollution by waste water and waste gas emission to the atmosphere, soil, and water bodies. While biomass resources can be non-harm processed for energy, it can help better rural environment and higher life quality for rural residents. Breath system disorder is a kind of frequent disease for rural women, which is considered correlative with habit of using straw as cooking fuel in Sub-Sahara Africa's rural areas. Biomass technologies can help provide clean energy and largely reduce the use of crop straw firing. Cleaner in-house environment will reduce the disease cases.

Currently rural area is the weakest in Sub-Sahara Africa's social and economic development, with backward infrastructures and slow farmer income growth. Biomass 
resources are mainly from agriculture and forestry. Therefore, development of biomass energy will contribute to the rural development. In terms of energy supply, due to the lagged infrastructure development, about 10 million rural residents still has no electricity access in Sub-Sahara Africa, that make them far from modern life style. In addition, about $80 \%$ of rural energy sources come from crop straws and fire woods, with very low energy efficiency. On the other hand, biomass resources are very abundant in the rural areas. Application of the biomass resources can help electric power supply at the remote rural areas. Fully use of the local biomass energy resources will provide rural residents with clean energy and improve their life quality.

For environmental benefits, biomass development and applications will improve rural productivity and life quality, and contribute to an energy saving and environmentally friendly social development. Through making use of the previously abandoned agricultural and forestry residues for energy by collecting and processing the resources, straw and livestock waste pollution can be effectively resolved and rural environment can be significantly improved. Meanwhile, application of the agricultural biomass will produce large amount of organic fertilizers. The more organic fertilizers can in turn improve soil organism and reduce usage of chemical fertilizers and pesticide.

While looking at social benefits, biomass development will promote rural industry and small township development, which will help smaller gap between urban and rural life standard. In conclusion, development of biomass energy will facilitate increased farmer's job opportunities and income, improved environment, reduced disease, and improved rural life quality. It will also help improved rural energy supply. With the significant environmental and social benefits, biomass energy sector development in rural area will become an effective and practical approach for promoting the modern agriculture and rural development program through biomass industry driving force.

\section{METHODOLOGY}

Biomass energy industry in Sub-Sahara Africa is still at its very early infancy stage. Assessment of a biomass technology is based only on its technical and economic level, lack of systematic comparative analysis on multiple technical processes. Meanwhile, due to the proliferation of many biomass technologies with different maturity and applications, it is difficult to compare among them.

Therefore, comparison of biomass technology benefits in resources, social and environmental aspects is usually qualitative without a quantitative assessment indicator system. So far, most of the studies on biomass technology development are qualitative in nature. The methodology used in this research includes the following three important components:

(1) development of an indicator system for evaluating biomass technologies;

(2) quantification of the evaluation indicators;

(3) using the evaluation system on the biomass technologies. The researcher designed a system of biomass technology evaluation indicators. By quantifying and applying the evaluation indicators, the biomass roadmap is studied and proposed in a systematic and quantitative method.

The biomass energy comprehensive evaluation indicator system developed in this research is a multiple criteria system covering technology, economy, resource, environment, 
and social factors into nine categories. Quantification of the indicators allows not only computation of external economic benefit of each technology, but also quantitative evaluation of future development perspectives. This makes possible the systematic comparative analyses of different biomass application technologies.

\section{Quantitative Assessment}

In this research, quantification of evaluation indicators is based on support of large datasets, while the quantification is the most challenging and also spot-light task. The task of quantification of the evaluation indicators will include the following aspects:

Firstly, design of a quantitative system of evaluation system. Generally, evaluation indicators of biomass energy shall include two groups: technological strength and overall benefits. The overall benefits are evaluated by capital investment cost and external benefits (including energy benefit, environmental benefit, and social benefit), that can be ranked by computational points, while technology strength can be assessed by three major indicators: technology maturity, technical obstacles, and intellectual property right ownership so that future biomass technology development strength can be evaluated by ranking method in order to identify stage-wise ranks of the biomass energy technologies.

Secondly, the indicators are quantifies by weights, scores, and quantitative standards, so that final scores can reflect future development strength of a particular biomass technology. Quantitative scores of each biomass technology are evaluated at three temporal points: current, 2015, and 2020. These quantitative assessments need large number of basic data sets. These include fundamental data on typical biomass application cases, understanding on current and future biomass technologies, which become bases of evaluation indicators and their quantification.

In this research, 10 biomass technologies are analyzed and quantitatively evaluated, including three agricultural and forestry residues for energy (direct firing, co-firing, gasification, pellet fuel, and pellet charcoal), two livestock waste for energy (in-grid biogas power and off-grid biogas power generation), two garbage for energy technologies (incineration and fill gas power generation), and three liquid bio-fuel technologies (bio-fuel ethanol from non-grain, ethanol from sugar plants, ethanol from cellulose feedstock, biodiesel from waste oil, and biodiesel from oil plants). The current status, development by 2015 and 2020 are analyzed quantitatively for the 10 biomass technologies on their investment, cost, energy benefit, social benefit, and environment benefit. At the same time, development potentials of each biomass technology are evaluated by scores. This allows systematic comparison within each type of biomass resources.

\section{Assessment Method}

To complete the quantitative analysis and design, applying a solid evaluation system is critical. This means that by utilizing the proposed comprehensive evaluation indicator system for the 10 biomass technologies, it is critical to design a roadmap based on the evaluation results.

First of all, biomass resource availability will be the most important indicator for the evaluation, as biomass technologies shall not compete in the market unless they utilize the same type of biomass resources. Therefore, the evaluation of biomass technologies is resource based. Future development potential of biomass technologies using a kind of resource are scored and ranked to achieve more reasonable and practical comparison result. 
In this research, biomass resources are classified into four categories: agricultural and forestry residues, livestock waste, life garbage, and resources for bio-fuels.

Biomass technologies for the same resource category are evaluated and compared for the development potential and comprehensive benefits. Based on the technology development trends, technical obstacles and corresponding measures at different stage are identified. It is shown from the research result that under appropriate measures, the biomass technologies under different resource categories can be technologically mature by 2020 and can meet the demand of biomass energy targets. To determine the scale and priority of biomass technology development, it depends not only on technological maturity, but also on many aspects of economy, energy, and social contributions of each biomass technology. The comprehensive benefit evaluation can produce clarified quantitative conclusion and development suggestions.

\section{The targets biomass energy development roadmap for Sub-Sahara Africa}

According to current research results by the ERI, the study defined biomass energy target by 2015 and 2020. By 2015, produced biomass for energy shall be totaled 51.79 million tons and 119 million tons by 2020, which include installed biomass power capacity of $34.50 \mathrm{GW}$, biogas of 112.7 billion $\mathrm{m}^{3}$, biomass pellet fuel of 30 million tons, and liquid biofuel of 12 million tons. Development targets for each biomass technology will be as the following Table 1-3.

Table 1. Biomass products developments for 2015 / 2020 projection.

\begin{tabular}{|c|c|c|c|c|}
\hline \multirow{2}{*}{ Technologies } & $\mathbf{2 0 1 5}$ & $\mathbf{2 0 1 5}$ & $\mathbf{2 0 2 0}$ & $\mathbf{2 0 2 0}$ \\
\cline { 2 - 5 } & Capacity & $\begin{array}{c}\text { Energy } \\
\text { equivalent } \\
\left(10^{4} \text { tce }\right)\end{array}$ & Capacity & $\begin{array}{c}\text { Energy } \\
\text { equivalent } \\
\left(10^{4} \text { tce }\right)\end{array}$ \\
\hline $\begin{array}{c}\text { Biomass power } \\
\left(10^{4} \mathrm{KW}\right)\end{array}$ & 1449 & 3192 & 3450 & 7494 \\
\hline $\begin{array}{c}\text { Fromcrop } \\
\text { straws }\end{array}$ & 675 & 1445 & 1618 & 3405 \\
\hline biogas & 407 & 882 & 1025 & 2193 \\
\hline msw & 367 & 865 & 807 & 1896 \\
\hline $\begin{array}{c}\text { Bio-fuel gas } \\
\left(10^{8} \mathrm{~m}^{3}\right)\end{array}$ & 163 & 1127 & 288 & 549 \\
\hline $\begin{array}{c}\text { Straw } \\
\text { gasification }\end{array}$ & 37 & 137 & 150 & 1087 \\
\hline biogas & 126 & 300 & 3000 & 1500 \\
\hline $\begin{array}{c}\text { Biomass pellet } \\
\text { fuel (10 }\end{array}$ & 600 & 560 & 1200 & 1043 \\
\hline $\begin{array}{c}\text { Liquid bio-fuel } \\
\left(10^{4} \text { tons }\right)\end{array}$ & 500 & 365 & 1000 & 538 \\
\hline \begin{tabular}{c} 
Fuel ethanol \\
\hline
\end{tabular}
\end{tabular}




\begin{tabular}{|c|c|c|c|c|}
\hline biodiesel & 150 & 195 & 200 & 261 \\
\hline Total & & 5179 & & 11933 \\
\hline & & & & \\
\hline
\end{tabular}

\section{ADOPTED FROM ERI.}

To fulfill the above targets, 78.36 million tons coal equivalent biomass resources will be consumed by 2015 and 17.901 billion tce by 2020, of which crop and forest residues will contribute to $50 \%$ of the total biomass resources. For detailed resource data, please see the following table 2-3.

\section{Biomass products developments - 2015 projection}

Table 2 shows the list of available technologies in Sub-Sahara Africa region and gives the investment cost for the more optimistic (RE) scenario, as well as the construction duration and the expected lifetime. The reduction in investment cost is due to technology learning anticipated from increased global installed capacity in those technologies, in combination with policies promoting increased local content. For fossil fuel based power generation the cost of fuel are critical. Diesel prices are projected to increase from 24 to 29 USD per GJ between 2015 and 2020. Gas supplied from transmission pipelines is projected to increase from 9 to $11 \mathrm{USD} / \mathrm{GJ}$ in the same period.

Local associated gas is considerably cheaper, rising from 4.5 to 9 USD/GJ. Domestic coal increases from 2.5 to 4 USD/GJ while imported coal is about $30 \%$ more expensive.

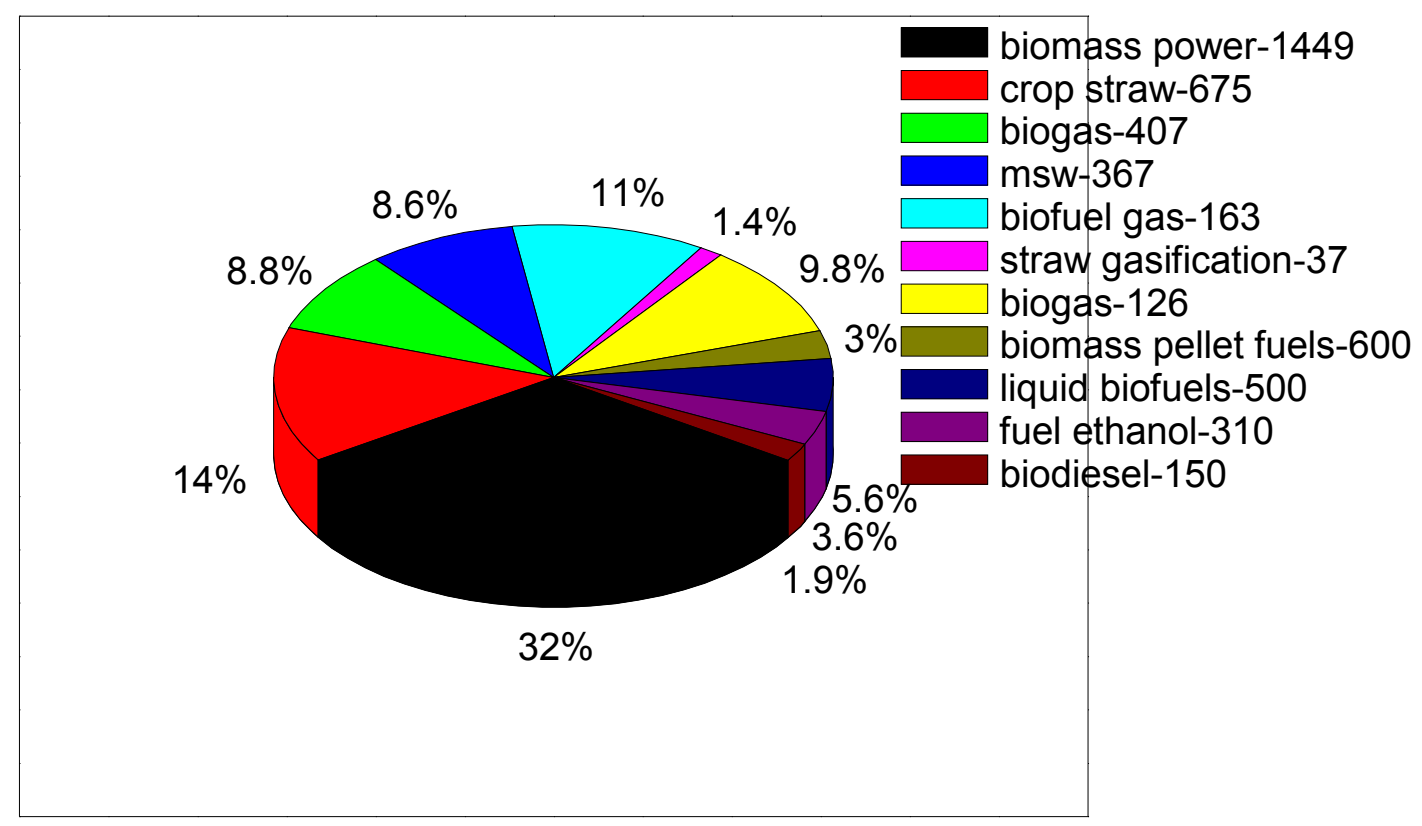



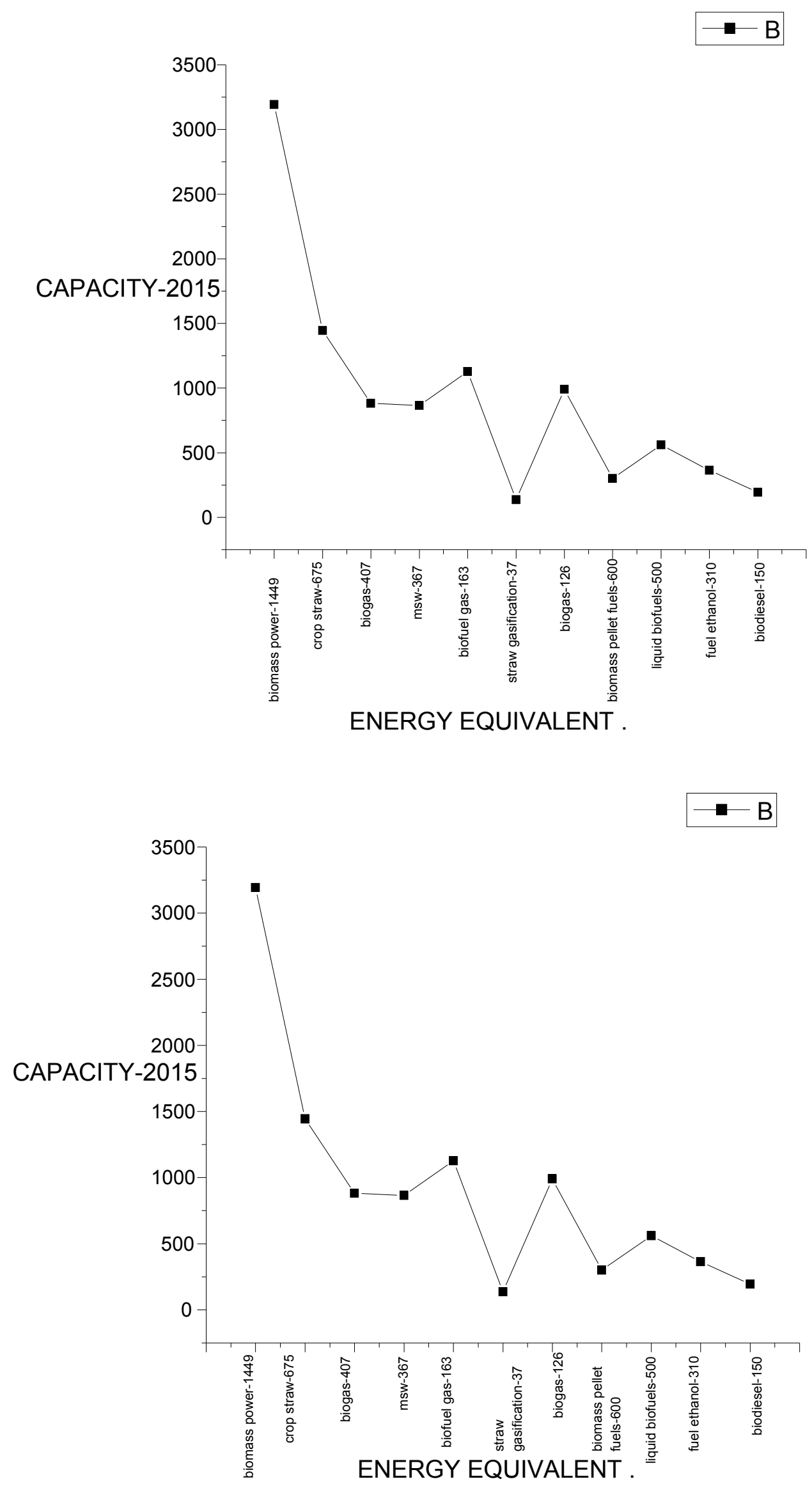


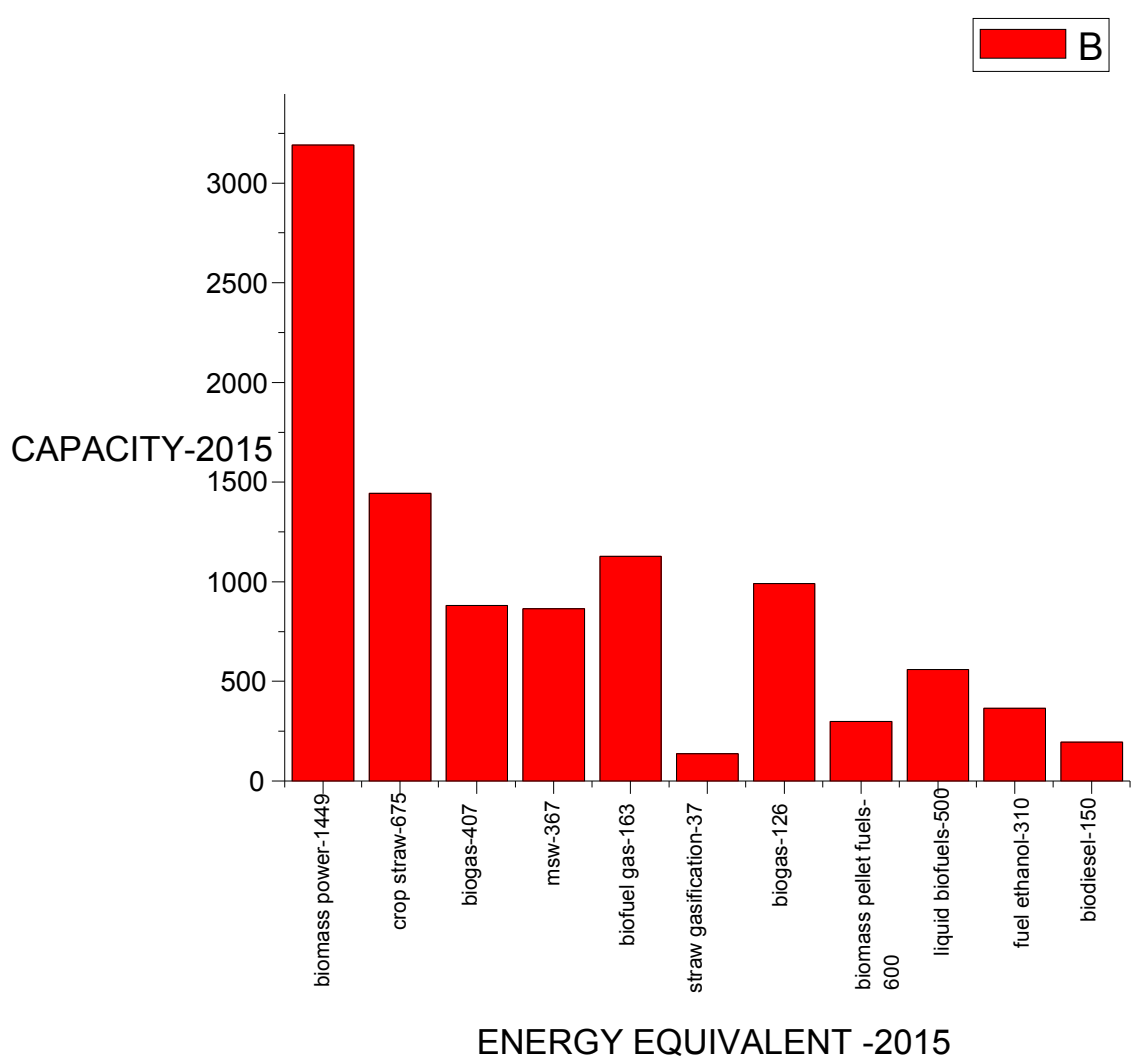

Biomass products developments $\mathbf{- 2 0 2 0}$ projection

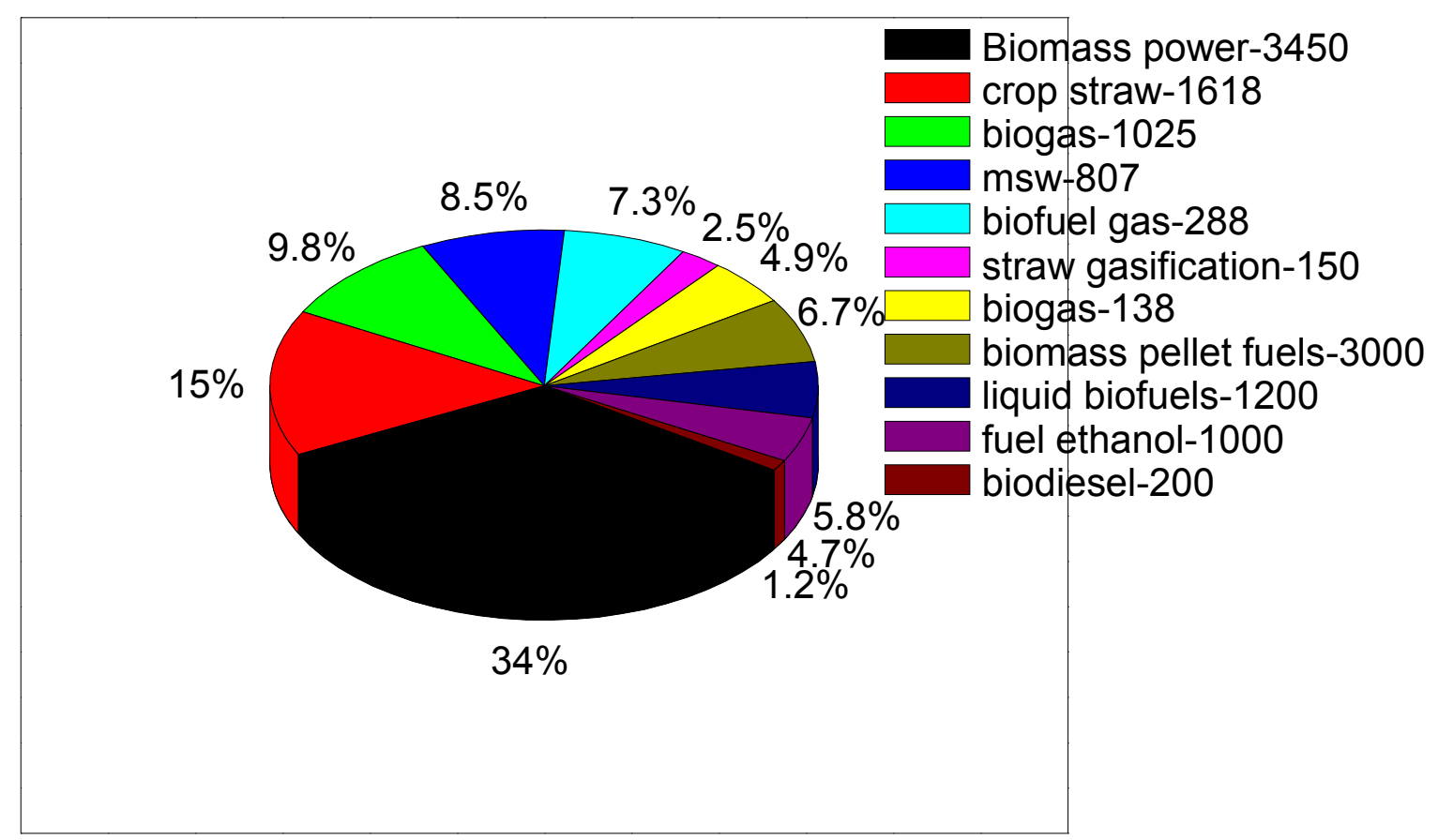




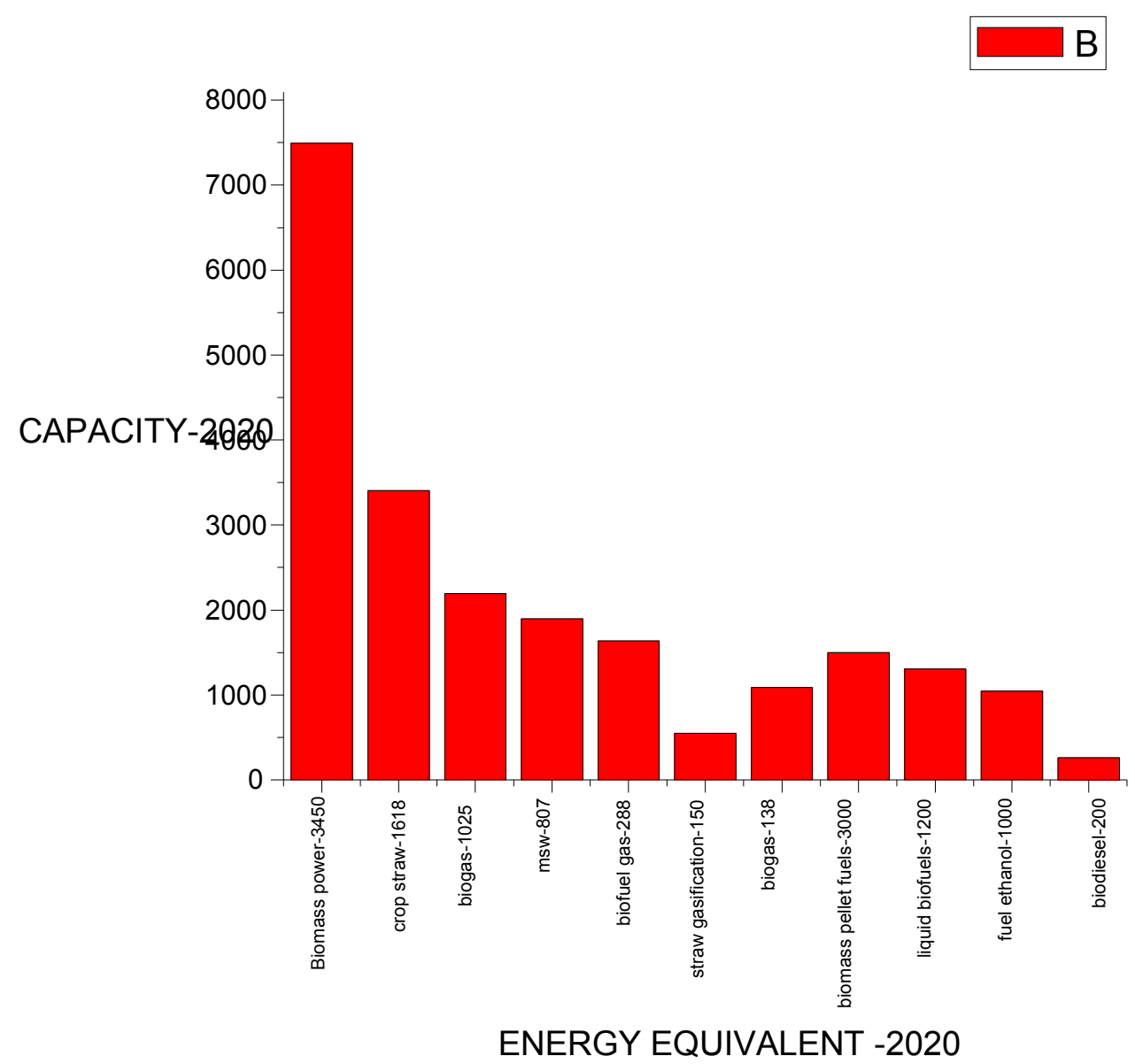

Table 2 shows the list of available technologies in Sub-Sahara Africa region and gives the investment cost for the more optimistic (RE) scenario, as well as the construction duration and the expected lifetime. The reduction in investment cost is due to technology learning anticipated from increased global installed capacity in those technologies, in combination with policies promoting increased local content. For fossil fuel based power generation the cost of fuel are critical. Diesel prices are projected to increase from 24 to 29 USD per GJ between 2015 and 2020. Gas supplied from transmission pipelines is projected to increase from 9 to $11 \mathrm{USD} / \mathrm{GJ}$ in the same period.

Local associated gas is considerably cheaper, rising from 4.5 to 9 USD/GJ. Domestic coal increases from 2.5 to 4 USD/GJ while imported coal is about $30 \%$ more expensive.

Table 2. Technology options and investment costs, re scenario in Sub - Sahara Africa.

\begin{tabular}{|c|c|c|c|c|}
\hline \multirow{2}{*}{$\begin{array}{c}\text { Technologies } \\
\text { Options }\end{array}$} & $\mathbf{2 0 1 0}$ & $\mathbf{2 0 1 5}$ & $\begin{array}{c}\text { Construction } \\
\text { duration }\end{array}$ & Life-Time \\
\cline { 2 - 5 } & USD/KW & USD/KW & Years & Years \\
\hline Diesel & 1,070 & 1,070 & 2 & 25 \\
\hline HFD & 1,350 & 1,350 & 2 & 25 \\
\hline
\end{tabular}




\begin{tabular}{|c|c|c|c|c|}
\hline OCGT & 603 & 603 & 2 & 25 \\
\hline CCGT & 1,069 & 1,069 & 3 & 30 \\
\hline $\begin{array}{c}\text { Supercritical } \\
\text { coal }\end{array}$ & 2,403 & 2,403 & 4 & 30 \\
\hline Hydro & 2000 & 2000 & 5 & 50 \\
\hline Small Hydro & 3,804 & 3,618 & 2 & 50 \\
\hline Biomass & 2,260 & 2,043 & 4 & 30 \\
\hline $\begin{array}{c}\text { Bulkwind } 25 \% \\
\text { CF }\end{array}$ & 1,808 & 1,634 & 2 & 25 \\
\hline $\begin{array}{c}\text { Bulkwind } 30 \% \\
\text { CF }\end{array}$ & 1,808 & 1.634 & 2 & 25 \\
\hline $\begin{array}{c}\text { Solar PV } \\
\text { (utlilty) }\end{array}$ & 1,631 & 1,474 & 1 & 25 \\
\hline $\begin{array}{l}\text { Solar PV } \\
\text { (rooftop) }\end{array}$ & 2,038 & 1,843 & 1 & 25 \\
\hline PV with battery & 2,854 & 2,451 & 1 & 25 \\
\hline $\begin{array}{l}\text { Solar thermal } \\
\text { no storage }\end{array}$ & 2,576 & 2,329 & 4 & 25 \\
\hline $\begin{array}{l}\text { Solar thermal } \\
\text { with storage }\end{array}$ & 4,637 & 4,086 & 4 & 25 \\
\hline $\begin{array}{l}\text { Solar thermal } \\
\text { with gas co- } \\
\text { firing }\end{array}$ & 1,320 & 1,288 & 4 & 25 \\
\hline
\end{tabular}

NOTE - CF - Capacity Factor, CCGT - Combined cycle Gas Turbine OCGT - Open cycle Gas Turbine.

Based on the above assumptions on the cost of development, a levelized cost of electricity (LCOE) analysis was performed. The LCOE was computed for the two abovementioned scenarios.

Results for both scenarios are shown in Table 3 and Table 4 for the base year and 2020. The results are presented for the power plant LCOE with and without levelized transmission and distribution costs. Transmission and distribution costs need to be added to certain large scale power options that require transmission and distribution lines. They do not apply for decentralized power generation units, or they will be significantly reduced in such cases. Also decentralized power does not face the same transmission and distribution losses as centralized power generation.

Three classes of consumers are distinguished as they are assumed to require different degree of transmission and distribution infrastructures. Three classes of consumers are:

- Heavy industry (e.g. mining), which connects to generation at a high voltage and generally requires less transmission and no distribution infrastructure. 
- Urban residential, commercial, and small industries, which are connected to generation via relatively more transmission and distribution infrastructure.

- Rural residential and commercial, which require even more transmission and distribution infrastructure.

Accordingly, transmission and distribution cost are assumed to vary by market segment. For industry, urban and rural consumers $1.5,5$ and $10 \mathrm{USD} \mathrm{C} / \mathrm{kWh}$ was assumed. Losses were set at 7, 15 and $20 \%$, respectively, and were kept constant over time. In comparison average losses in other region are well below $8 \%$. High losses favour decentralized solutions. The levelized cost of electricity data in Table 3 shows that for industrial customers connecting at high voltage, hydropower is the cheapest option, closely followed by combined cycles using associated. However, this situation changes in 2020, with the escalation in fuel price. For region that have domestic coal, coal generation is the next cheapest option but this is closely followed by wind with high capacity factors. Next is natural gas based on imported gas and power generation based on imported coal. This is followed by biomass. PV utility and solar thermal are the next options for region without any other domestic resources. The optimal mix is different for rural areas. For rural customers, mini hydro remains the best option, where it is available. Distributed/ roof-top PV with and without battery are expected to become the next best option for these customers in the RE scenario.

Table 3. LCOE comparisons' for 2015 - 2020 in Sub - Sahara Africa.

\begin{tabular}{|c|c|c|c|c|c|c|}
\hline $\begin{array}{c}\text { LCOE } \\
\text { USD/MWH }\end{array}$ & GRID & BAU-T & RE & $\begin{array}{c}\text { RE TND } \\
\text { IND }\end{array}$ & $\begin{array}{c}\text { RE TND } \\
\text { URBAN }\end{array}$ & $\begin{array}{c}\text { RE TND } \\
\text { RURAL }\end{array}$ \\
\hline Diesel & 0 & 326 & 326 & 326 & 326 & 326 \\
\hline HFD & 1 & 154 & 208 & 238 & 295 & 360 \\
\hline OCGT & 1 & 69 & 154 & 180 & 231 & 292 \\
\hline CCGT & 1 & 104 & 98 & 120 & 173 & 222 \\
\hline $\begin{array}{c}\text { Super } \\
\text { critical coal }\end{array}$ & 1 & 84 & 89 & 89 & 154 & 187 \\
\hline Hydro & 1 & 62 & 62 & 127 & 123 & 213 \\
\hline Small hydro & 0 & 102 & 102 & 110 & 102 & 211 \\
\hline Biomass & 1 & 104 & 104 & 82 & 173 & 178 \\
\hline $\begin{array}{c}\text { Bulkwind } \\
25 \% \text { CF }\end{array}$ & 1 & 111 & 111 & 102 & 181 & 102 \\
\hline $\begin{array}{c}\text { Bulkwind } \\
\text { 30\% CF }\end{array}$ & 1 & 94 & 94 & 127 & 160 & 231 \\
\hline $\begin{array}{c}\text { Solar PV } \\
\text { (utlility) }\end{array}$ & 1 & 107 & 107 & 134 & 175 & 239 \\
\hline $\begin{array}{c}\text { Solar PV } \\
\text { (rooftop) }\end{array}$ & 0 & 159 & 159 & 116 & 159 & 217 \\
\hline $\begin{array}{c}\text { PV with } \\
\text { battery }\end{array}$ & 0 & 201 & 201 & 130 & 201 & 283 \\
\hline
\end{tabular}




\begin{tabular}{|c|c|c|c|c|c|c|}
\hline $\begin{array}{c}\text { Solar } \\
\text { thermal on } \\
\text { storage }\end{array}$ & 1 & 125 & 125 & 159 & 196 & 159 \\
\hline $\begin{array}{c}\text { Solar } \\
\text { thermal with } \\
\text { storage }\end{array}$ & 1 & 149 & 149 & 201 & 226 & 201 \\
\hline $\begin{array}{c}\text { Solar } \\
\text { thermal with } \\
\text { gas co-firing }\end{array}$ & 1 & 112 & 112 & 136 & 182 & 240 \\
\hline
\end{tabular}

\section{DISCUSSION OF RESULTS AND CONCLUSIONS}

Power supply is projected to grow from 51 TWh in 2015 to 247 TWh in 2020 (a fivefold increase). This huge demand increase creates great opportunities to deploy renewable energy technologies.

The fossil power generation mix in 2020 includes 94 TWh of gas and 18 TWh of coal. The gas is largely associated gas, a low-cost by-product from oil production. This gas supply is limited to those region with significant oil production. Significant efforts are ongoing to increase the use of this gas, part of which is flared today. The associated gas production ceases a few years after oil production is stopped. The share of renewables in power generation would be $22 \%$ in 2015 .

In the RE scenario it will rise to $54 \%$ in 2020 . Three quarters of this renewable power supply in 2020 is regional hydropower, supplemented by imported hydropower from other African region. With more trade in the RE scenario, the share of hydro (within the region) and imported hydro from other African region will increase relative to BAU-T. Solar and biomass would start to emerge in 2020, but solar wind and import of hydro grow significantly after 2020. While fossil power plant additions dominate 2015-2020, the majority of power plant additions after 2020 are based on renewables. This result can be explained by the fact that the best hydropower resources are exhausted past 2020. It is a surprise that no more wind and solar is applied prior to 2020. The LCOE data in Table 3 explain this result. In rural electricity markets renewables constitute the favoured option. However, the size of this market is limited. Centralized renewable power options face the same high transmission and distribution cost as fossil fuels. Moreover in the largest markets, like Nigeria Senegal and Côte d'Ivoire, low cost associated gas based power generation dominates. The availability of this gas in the coming decades needs to be assessed in more detail. It should also be noted that the scenarios do not assume any $\mathrm{CO}_{2}$ pricing. Sensitivity analysis suggests that of a $\mathrm{CO}_{2}$ price were considered the share of renewable would rise further at the expense of fossil fuels.

\section{Need to promote the use renewable energy in Africa}

Given the large renewable energy potential that exists in Africa, it is only logical that these indigenous resources are used and promoted. Furthermore renewable energy offers diversification in energy supply, thus strengthening energy security by broadening national energy generation portfolios. Countries with diversified energy generation are better-off than those which heavily depend on centralized large-scale hydro or conventional thermal based generation, as the former is dependent on rainfall and the latter on imported petroleum fuels both of which can have a degree of uncertainty in supply. Reliance on a narrow range of energy supply options can lead to an energy crisis. Renewable energy can contribute to 
lowering the risk profile of a country's energy sector. The energy sector in numerous African countries is characterized by high oil import bills, accounting for a significant proportion of export earnings (Karekezi and Kimani, 2001; AFREPREN, 2001). In addition, high oil imports increase the vulnerability of African countries to external oil price shocks which have an adverse impact on balance of payments. The use of renewable energy sources can reduce dependence on imported petroleum fuels (Mbuthi, 2004; Yuko, 2004). Table 4 estimates the potential for replacing electricity generation from fossil fuels by biomass-based cogeneration in three Eastern and Horn of Africa countries.

Table 4. Potential of cogeneration to replace electricity generation from fossil fuels.

\begin{tabular}{|c|c|c|}
\hline Country & $\begin{array}{c}\text { Electricity generation from } \\
\text { oil \& petroleum }(\mathrm{GWh})\end{array}$ & $\begin{array}{c}\text { Biomass-based } \\
\text { cogeneration potential } \\
(\mathrm{GWh})\end{array}$ \\
\hline United Rep. of Tanzania & 143 & 315 \\
\hline Kenya & 1,509 & 2,606 \\
\hline Ethiopia & 19 & 1,750 \\
\hline
\end{tabular}

SOURCES - Adapted from IEA, 2003

This is best illustrated by power sectors in the three East African countries. In the United Republic of Tanzania and Uganda, the power sectors are predominantly large-scale hydro. Due to prolonged drought during the period of 2005/2006, the water level in the hydropower dams was very low leading to severe electricity generation shortfalls. Consequently, the two countries have been experiencing load shedding lasting about eight hours a day. By contrast, Kenya's power sector has a much lower risk profile as it has several electricity generation options including hydropower, geothermal, thermal and a limited amount of wind energy. While the drought of 2005/2006 affected its hydropower dams, the availability of other renewable energy options contributed to a steady supply of electricity.

Another important reason for Africa to promote renewables is to enhance the competitiveness of its agricultural commodities. For agro-processing industries such as coffee, tea, sugar, sisal and cotton located in remote areas (sometimes away from the grid), embedded renewable-based generation can lower energy costs, thereby making the products competitive in the world market. Embedded generation can also contribute to the stability of the national or local grid where agro-processing industries are connected. The failure of conventional energy systems to reach the majority of the population should be a strong incentive for African governments to promote renewables. For example, after more than 40 years of independence, the majority of the population, especially the poor, still have no access to modern energy services such as electricity. On the other hand, there is growing evidence that investment in small and medium-scale renewable energy technology projects, e.g. small-hydro, could be an important option for providing modern energy services to the poor, particularly those residing in remote and scattered rural settlements (Mapako and Mbewe (eds.), 2004; Karekezi and Kithyoma, 2002; UNDP, 2004; World Bank, 2004). Renewable energy can play an important and cost-effective role in rural electrification, particularly in areas far from the grid. 
There are several reasons for Africa to promote energy efficiency. First and foremost, the rate at which energy demand increases in many sub-Saharan African countries appears to be outpacing the rate at which energy supply is being increased. Therefore, an obvious option is the implementation of energy efficiency measures that would free up supply capacity to meet the rising demand.

Secondly, the worsening energy crisis in the region has served as a "wake-up call" to the region's policymakers on the importance of energy efficiency. In the electricity subsector, drought-induced generation capacity short falls are becoming prevalent. In the petroleum subsector, the steep increase in world oil prices is having a devastating effect on sub-Saharan African economies. Energy efficiency programmes would help to mitigate the adverse impacts of these crises.

Thirdly, with the gradual withdrawal of donor participation in the financing of largescale energy investments, alternative financial resources are limited and expensive. Therefore, implementation of energy efficiency programmes could delay the need for new investment in additional/enhanced energy supply infrastructures. This is especially important for African countries, which are often capital constrained.

Fourthly, energy efficiency measures can "shave off" peak loads in a power system thereby minimizing the need for huge investments to meet peak demand which lasts for only a few hours in a day. For example, the peak load experienced in the mornings is often associated with water heating. Therefore, using energy efficient water heating technologies such as solar water heaters can "shave off" a significant amount of the peak load.

Fifthly, energy efficiency measures can significantly reduce the cost of energy supply. For example, in Tunisia where a major programme of the national utility is promoting solar water heaters, it is estimated that by converting water heating systems to use solar only, it can reduce the utility's cost of electricity supply by about 20 per cent (Awerbuch, 2005).

Sixthly, the high cost of energy in the industrial sector in sub-Saharan African countries is eroding the competitiveness of their products in the local, regional and international markets (GEF-KAM, 2005). Therefore, industrial energy efficiency measures reduce the cost of production thereby enhancing competitiveness, especially where commodity prices are not set by the producer. For example, the world price of tea is not set by the respective producing countries.

Therefore, to ensure the profitability of tea production, tea factories have to keep their cost of production (especially energy costs) as low as possible. A comparison between two competing regions, i.e. Eastern Africa and Sri Lanka, reveals that the cost of energy for tea production in Eastern Africa accounts for a larger proportion of the cost of production than in Sri Lanka.

The significant difference is essentially due to lack of energy efficiency measures and the limited use of abundant renewable small hydro resources that are often found in teagrowing regions Another reason why Africa should promote energy efficiency is that it can generate jobs. For example, the production of energy efficient charcoal and fuelwood stoves has provided a significant amount of employment opportunities in urban and rural areas. An ideal illustration is the introduction of the Kenya ceramic jiko - an energy efficient charcoal stove - which is currently produced by over 200 businesses, the bulk of which are informal sector manufacturers (Solutions Site, 2006).

Lastly, the promotion of energy efficiency in Africa can help in arresting environmental degradation such as deforestation and associated soil erosion caused by charcoal production; indoor air pollution caused by the use of traditional biomass; and local air pollution associated with thermal electricity generation. In addition, the climate change benefits 
accrued from energy efficiency can attract CDM-related financing and grant financing from agencies such as the Global Environment Facility (GEF).

\section{References}

[1] ADB (1996). Environmental Impacts of Renewable Energy Systems in Africa, Abidjan, Côte d'Ivoire: African Development Bank (ADB).

[2] AFREPREN (2001). AFREPREN Occasional paper No. 5: Power Sector Reform in Africa - Proceedings of a Regional Policy Seminar, Nairobi, AFREPREN.

[3] AFREPREN (2004). African Energy Data and Terminology Handbook: Year 2003-2004 Edition, Nairobi, AFREPREN.

[4] Akarakiri J. B. (2002). "Rural Energy in Nigeria: The Electricity Alternative", Proceedings: Domestic Use of Energy, International Conference Towards Sustainable Energy Solutions for the Developing World, 2-3 April, 2002, Cape Technikon, Cape Town, South Africa.

[5] ASE (1998). Power Smart: Easy Tips to Save Money and the Planet, Washington DC, Alliance to Save Energy (ASE).

[6] Berdai M. (2001). "Renewable Energy in Morocco: Limits and Prospects", Proceedings of the African High-Level Regional Meeting on Energy and Sustainable Development for the Ninth Session on the Commission on Sustainable Development, Denmark, UNEP.

[7] Collaborating Centre on Energy and Development. Beehary R.V. (1996). The State of Renewable Energy Resources Development in Mauritius, Mauritius, University of Mauritius.

[8] Brew-Hammond A. (1995). Institutional Framework for Diffusion of Solar Technologies in Developing Countries, paper prepared for the ISES Solar World Congress, Harare, Zimbabwe, September 1995.

[9] Deepchand K. (2001). Bagasse-Based Cogeneration in Mauritius-A model for Eastern and Southern Africa. AFREPREN Occasional Paper No.2, Nairobi, AFREPREN.

[10] EAAL (2003). Sustainable Energy Solutions for Africa, Nairobi, Kenya: Energy Alternatives Africa Limited (EEAL).

[11] Edjekumhene I., Brew-Hammond A. (2001). "Barriers to the Use of Renewable Energy Technologies for Sustainable Development in Ghana", Proceedings of the African High-Level Regional Meeting on Energy and Sustainable Development for the Ninth Session on the Commission on Sustainable Development, Denmark: UNEP.

[12] Ekouevi (2001). "An Overview of Biomass Energy Issues in sub-Saharan Africa", Proceedings of the African High-Level Regional Meeting on Energy and Sustainable Development for the Ninth Session on the Commission on Sustainable Development, Denmark: UNEP Collaborating Centre on Energy and Development.

[13] EIA (2004). Egypt, www.eia.doe.gov, Washington D.C., USA: Energy Information Administration (EIA).

[14] EIC (2002). Best Practice Guide: Economic and Financial Evaluation of Energy Efficiency Projects and Programs, Colorado, Ecoenergy International Corporation (EIC). 
[15] Enda (1994). Assessment of Solar and Wind Energy Utilisation in Africa, Dakar, Enda.

[16] Ezzati M., Kammen D. M. (2002). "Household Energy, Indoor Air Pollution and Health in Developing Countries: Knowledge Base for Effective Interventions", Annual Review of Energy and the Environment, Vol. 27, California, Annual Reviews Inc.

[17] GEF (1992). Market Penetration to Solar Heating in Tunisia, Washington D.C., Global Environment Facility (GEF).

[18] GEF (1998). Tunisia - Experimental Validation of Building Codes and Removal of Barriers to their Adoption, www.gefweb.org/wprogram, Washington D.C., USA: Global Environment Facility (GEF).

[19] IEA (2003). Energy Balances of Non-OECD Countries, 2000-2001, Paris, International Energy Agency (IEA).

[20] IEA (2004). World Energy Outlook, 2004, Paris, International Energy Agency (IEA).

[21] IEA (2005). Energy Balances of Non-OECD Countries, 2002-2003, Paris, International Energy Agency (IEA).

[22] Kammen D., Kapadia, K. and Fripp, M. (2004). Putting Renewables to Work: How Many Jobs Can the Clean Energy Industry Generate?, Berkeley, University of California.

[23] Karekezi S. (1996). Solar Energy for Development in Sub-Saharan Africa - Status and Prospects, Nairobi, AFREPREN.

[24] Karekezi, S. (2002b). "Renewables in Africa - Meeting the Energy Needs of the Poor", Energy Policy, Vol. 30 Nos. 11-12. Special Issue - Africa: Improving Modern Energy Service for the Poor, Oxford, Elsevier Ltd.

[25] Karekezi S., Turyareeba P., Ranja T. (1995). Renewable Energy Technologies:

Research for Dissemination and Implementation (second draft), Stockholm and Nairobi, SEI and AFREPREN, pp. 26-30. 